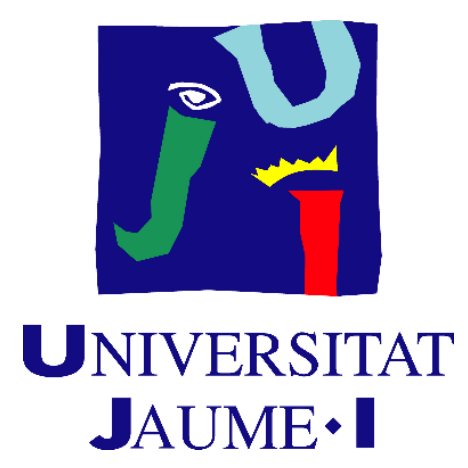

Trabajo Fin de Grado

\title{
LA VIOLENCIA FILIO-PARENTAL
}

\author{
Presentado por: \\ Laura Espadas Chirivella
}

Tutor/a:

Salvador Seguí Cosme

Grado en Criminología y Seguridad

Curso académico 2019/20 


\section{ÍNDICE}

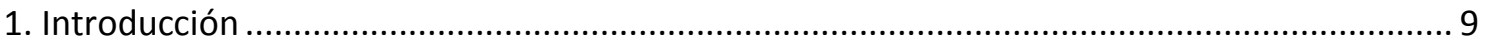

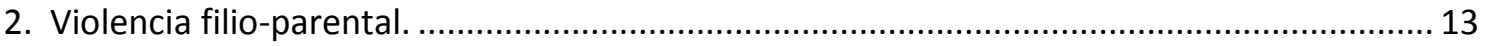

2.1 Definición, tipos de violencia filio-parental y características............................................... 13

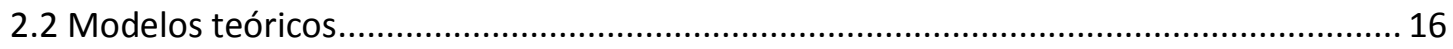

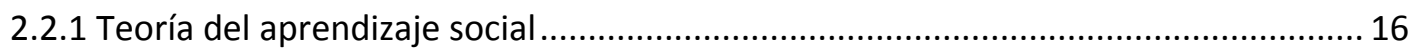

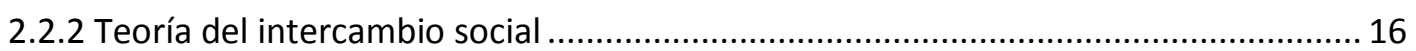

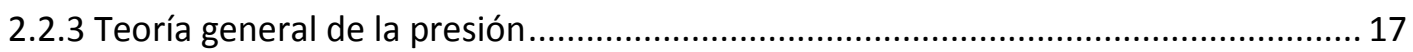

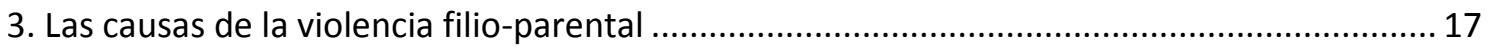

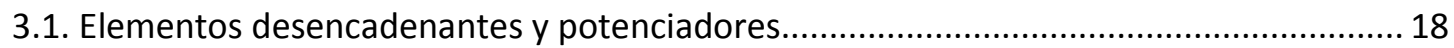

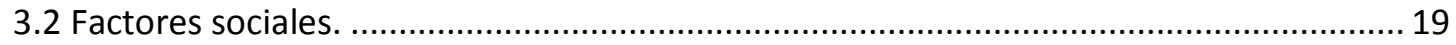

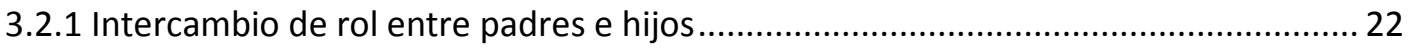

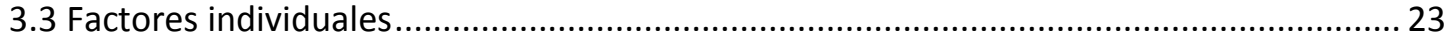

3.3.1 De puertas para afuera. Características de los agresores....................................... 25

3.3.1.1 Narcisismo y rasgos psicopáticos................................................................... 25

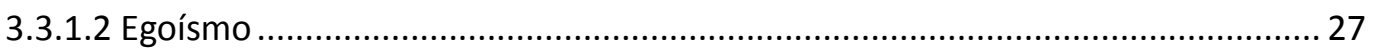

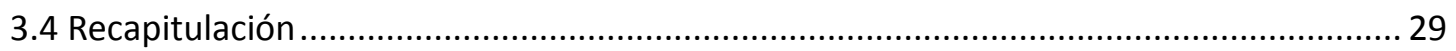

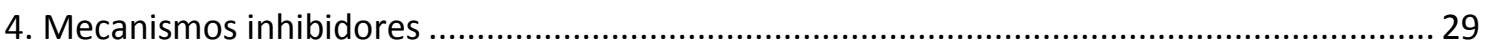

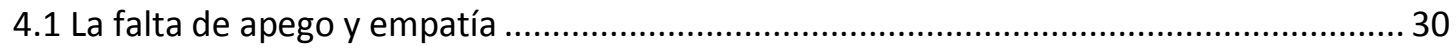

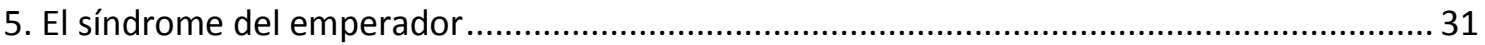

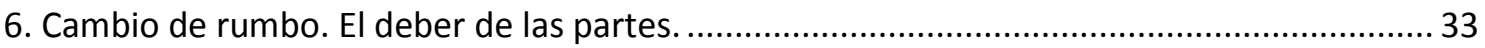

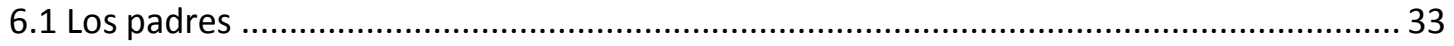

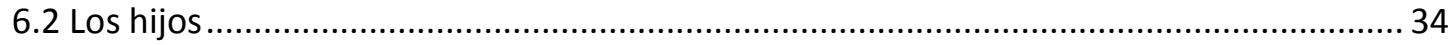

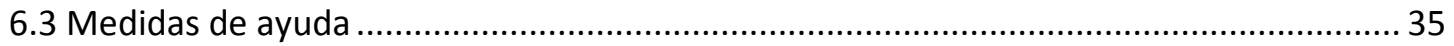

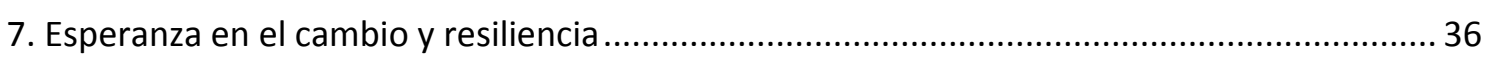

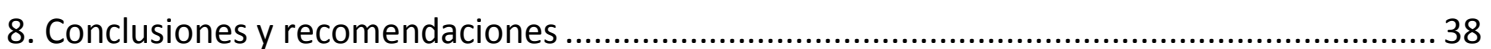

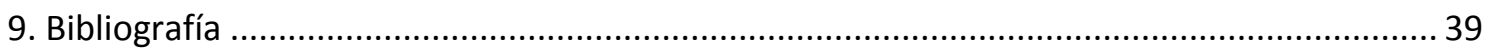




\section{Extended Summary}

Nowadays we know different types of violence, among these types we find some that prevail over others because of the number of cases that exist or the impact that they generate in society. We know that violent reactions are common in any human being since the aggressiveness that develops is a biological element with which we are born. Now, when people repeatedly engage in violent behavior for insignificant reasons, and even when we come to assault another person, whether a friend or a relative, we will say that it goes far beyond the biological elements with which we are born, talking then of a series of actions that are listed in the laws as a prohibition. For example, attacking physical, mental integrity.

We are going to talk about filio-parental violence, a type of violence that is found within the family and that develops normally within the home. In general people know all kinds of characteristics and data about gender violence because it is the type that has the most impact on society, so they forget other types of domestic violence that are having more and more impact. Knowing that society is not aware of the problem of filio-parental violence, we can say that it is a submerged phenomenon. And it is up to us to change these people so that in the future they do not become violent adults who violate the rights of their parents and in general of everyone who gets in their way.

That said, the first part of the work will begin by referring to quantitative data on the number of cases known in Spain, a large number of wich remains generally oberlooked. The problem with this point is that not all families who suffer the mistreatment of their children dare to denounce, since we will be speaking as this point says of a hidden reality, where we know what is registered with the Attorney General's Office, but not cases where parents do not report and end up living with an aggressor son for the rest of their lives. We will refer to the autonomous communities that prevail in violent behavior of children against parents in Spain, being these Andalusia, Valencian Community and Madrid.

Next, at this point we will also talk about what has happened so that today there has been an increase in this type of violence compared to the 1990s, defining this phenomenon as a type of sensitive violence due to the emotional burden of parents on their children. The reason for growth in relation to the 1990 s will be in the resurgence of previously known Latino bands, for example, and, above all, the influence of the media, since we currently live in a society where television is seen every day and there are at 
least two televisions per house. The problem in the media is that all the violent and aggressive acts that can be witnessed in society are seen on television, we talk about manifestations where there is aggression, fights, gender violence every day that lead to murders of husbands against women etc. Watching this kind of news every day makes people normalize that these events happen because it is something that we see on a daily basis.

In the second point we will address the main content, with the definition of filio-parental violence, the different types of behaviour it gives rise to, such as physical, verbal or economic violence and the characteristics that form it. When we have explained this, we will talk about three theoretical models that after years of research, give an answer to why there are people who end up developing this type of violent behavior. We will then speak of the theory of social learning as exposure from childhood to a violent environment, the theory of social exchange as the reward that the individual will receive from a third party and the general theory of pressure in relation to the behavior that an individual adopts to satiate his anger and frustration.

Once we have reached point three of the paper, we will talk about what factors influence the teenager to engage in violent behavior against his parents. We will classify it into a series of elements that together with individual and social factors will result in such behavior. The sum of these three aspects does not correspond to all adolescents who commit acts of violence against their parents, however, they are entitled to the sum of certain characteristics which are reflected in the enabling and triggering elements and social and individual factors.

About social factors, five social causes that will influence the development of the aggressor, the conscience, the single parent families, the stress with which many parents live, late responsibility and the consumerist society in which we currently live. Having explained these three points, we will talk about the educational model that parents would have to adopt to prevent their child from becoming an aggressive person. Before beginning the fourth point we will make a recapitulation of the elements and factors commented in the previous points as a summary to make it simpler and visually.

The last part of point three talks about individual factors at a concrete level will talk about possible mental illnesses that the individual may have, making special reference to three types of antisocial disorders, these being the behavior disorder, dissocial disorder and attention deficit hyperactivity disorder. These types of disorder are characterized by different aspects, but they have in common a number of them such as not respecting social norms or the rights of other people, not to integrate in a good way into society 
because they do not trust anyone and the only thing that interests them is what they want to obtain.

In addition, we will relate this type of mental disorder to the possible use of toxic drugs that may affect previously or as an enhancer. The abuse of toxic substances in the previous sense may give rise to violent behaviour due to the need to obtain money in order to obtain them, and, in an empowering way, we refer to the side effects that most drugs have and especially when they are used excessively.

As for individual factors, in addition to talking about the disorders discussed above and the consequences of using toxic drugs, we will also talk about what behavior the aggressor adopts when he is not at home. Throughout the work we will comment that the families that suffer this type of violence are difficult to detect since the aggressive acts are carried out inside the house not outside, then we will explain at the end of the point three characteristics that are easy to detect when the subject is away from home. We will then talk about the narcissism and selfishness that characterize this type of people as two characteristics that can be observed in the day-to-day life of the aggressor.

At point four we will explain why the young man who ends up assaulting his parents on a daily basis does not feel any remorse or guilt. As it happens in most people, when we commit some kind of misconduct towards a family member, we repent and feel the need to ask for forgiveness, On the other hand, these types of individuals never feel the same feeling and therefore the violence is increasing. We will then talk about the mechanisms that inhibit these feelings, attachment and empathy.

Point five talks about the so called emperor syndrome. When within a family the phenomenon of filio-parental violence has reached the maximum degree of violence, it is said that the aggressor's son suffers from the emperor's syndrome. It is when the family sees no way out and live in a continuous hell, the son can commit suicide and even kill his own parents, he does not accept anything that is said to him and imposes his rules inside the house. We will say then that it is the highest level at which filio-parental violence can reach, a level that hardly has a solution, and if it does, it would have to be intervened with the help of professionals.

Once we have explained the concept of the emperor's syndrome, and everything related to this type of violence, we will move on to point six. This point speaks of a number of fundamental aspects that parents and children would have to adopt in order for a change in the family to be possible. 
First, parents should be aware that they have a problem and need a solution so that in the future their teenager does not become an aggressive and marginalized adult. After this recognition, they would have to adopt a solid and authoritarian behavior at home so that the son could see that the control is not his, but his parents. And finally, throughout the process of change, parents have to be strong and courageous because one of the reasons why the child ends up violently attacking their parents is because they have never set a set standard for them to follow, and when they have done so, it has served no purpose because of the lack of rigidity and security with which they demonstrated compliance with those standards. The teenagers we're talking about are cold, intelligent people who, when they see a weak person and can use them for a profit, don't hesitate to attack their moral and physical integrity, Therefore, it is important that parents adopt a safe and firm role so that children see that the role of educators and authority is theirs, not theirs.

As for the children, they should be aware and accept that the violent behavior they use against their parents in the end is not effective and that, instead of winning, they lose.

The third and final point in paragraph 6 refers to the general measures that would have to be taken for the possible solution of the problem. First we will talk about a measure that involves the whole of society, then measures that should be taken by parents regardless of what was said in the previous point, another measure on a possible home care programme to help parents and children through social workers and, finally, the relationship between schools and the family in order to understand what is happening at home and how to help from school.

On point seven, we will talk about the change that parents can expect after asking for professional help and adopting the change themselves at home. We will show that the change that can be achieved will not consist in being a person who has been reborn and will never again have those characteristics that enhanced his temperament and his violent behavior, but surely with the change it will be possible for the subject to know how to differentiate between what is right and what is wrong, and above all to know how to control himself in situations in which he did not before. We will explain that it must be taken into account that this type of person was born with a personality and a character, and although they have changed in the way they treat their parents, At some point, he can jump in some bad ways, thereby demonstrating the character we were talking about.

In addition, in this section number seven, we will also refer to the term resilience as the ability of people to overcome negative circumstances and to approach their lives 
towards a future free of problems and negative burdens. We will explain what characteristics a person has to have in order to be resilient and that the problems are easier, for example, self-confidence, the type of people you surround yourself with etc.

And finally, about point eight of the work that will form it a conclusion and a set of recommendations focused on what we should do to all people who know families living with this problem, being empathetic and supportive in order to normalize the situation and give the necessary support to both parents and children who suffer from this type of violence.

Throughout the work we will have explained the meaning of filio-parental violence, the characteristics that make it up and in which forms it can be manifested, also the reasons or causes why a child may attempt to harm the integrity of his or her parents and why he or she does not feel any remorse after abusing them, We have also spoken of the emperor's syndrome as the highest degree of filio-parental violence, where the situation has been overwhelmed and the danger that exists is of the utmost gravity. Once the work is finished we will understand that it is not an easy task to redirect the lives of these young aggressors, but by taking the measures explained and especially having the professional help that is necessary at any moment, it will be possible to deal with the problem.

When all the people who involve the teenager in his day-to-day life as can be the group of family members, the classmates, the friends with whom he interacts, the teachers and also the professional help, they come together to change the situation that the family and that teenager live in, the problem gets smaller because the help is bigger.

To conclude this summary we will say that what is intended with this work is to publicize this type of violence every day more common and to reflect what it means to have this problem at home. To make understand the difficulty that requires to take the step to denounce our own children and the possible measures that can lead to prevent the case to stop it. 


\section{Resumen:}

El objetivo de este trabajo es conocer las causas que dan lugar a la violencia filio-parental y de qué manera influye en los hijos. Indagar sobre los factores de riesgo sociales e individuales desencadenantes y así abordar una serie de conclusiones que nos guíen hacia la posible solución del problema.

Entendemos la violencia doméstica como todo tipo de maltrato ejercido en el seno de la unidad familiar y dentro de esta, la violencia filio-parental es la llevada a cabo de hijos a padres, ahora bien, ¿qué es, en qué consiste dicha violencia y qué comportamiento adoptan los hijos frente a los padres?

A lo largo del trabajo hablaremos de las diferentes formas en las que se puede manifestar dicha conducta, qué es lo que le ocurre al sujeto para llegar a cometer estos actos agresivos contra sus padres sin ningún tipo de sentimiento de culpa o arrepentimiento. Conoceremos el llamado síndrome del emperador y posteriormente abordaremos una serie de medidas para poder hacer frente a este fenómeno.

Palabras clave: padres, adolescentes, violencia filio-parental, comportamiento violento, factores de riesgo, síndrome del emperador, medidas preventivas, joven tirano.

\section{Abstract:}

The aim of this work is to know the causes that give rise to filio-parental violence and how that affects children, to investigate social and individual risk factors triggered due to this type of violence, and consequently, approach a number of conclusions that provide us the possible solution to that problem.

We understand domestic violence as all types of abuse committed within the family unit and filio-parental violence, is the violence commited by children against parents. However, what does that term mean? What does it consist of? And what is the behaviour of children have towards their parents?

Throughout the work, we will talk about the different ways in which such behavior can be manifested, we will analyse what happens in the individual to get to commit these aggressive acts against his parents without any feeling of guilt or repentance and we will 
know the so-called "emperor syndrome". Finally, to bring the matter to a conclusion, a series of measures will be addressed to be able to confront this phenomenon.

Keywords: parents, teenagers, filio-parental violence, violent behavior, risk factors, emperor syndrome, preventive measures, young tyrant.

\section{Introducción}

La violencia filio-parental es un tipo de violencia de la que se habla poco, y cuando se hace siempre es sobre los casos más impactantes. En cambio, si hablamos del tipo de violencia que más repercusión tiene en la actualidad sería la violencia de género, esto se debe al gran altavoz que ejercen los medios de comunicación en este terreno, debido a la casuística y al fatal desenlace que se da en muchos casos. La palabra muerte es alarmante, pero lo es más saber que en la mayoría de los casos lo ha ocasionado la pareja o expareja de la víctima, esto ha creado un gran movimiento y repercusión en la sociedad.

Entonces, ¿en qué lugar queda la violencia ejercida de hijos a padres? ¿Cuándo aparecen las primeras pruebas de la existencia de este tipo de violencia tan poco conocido por la sociedad?

Podemos encontrar estudios e investigaciones sobre la violencia filio-parental a nivel general, es decir, tipos de conductas que abarca, teorías del porqué de este comportamiento, características potenciadoras del sujeto activo y pasivo que dan lugar a esta tipología etc. Pero si queremos indagar sobre casos concretos, la información que encontraremos será por las denuncias presentadas por padres contra sus hijos, desconociendo entonces los casos de las familias que padecen también el fenómeno pero no llegan a presentar denuncia alguna.

A lo largo del trabajo abordaremos este tipo de conducta de principio a fin, es decir, introduciremos el tema hablando de los casos que se conocen en España durante los últimos años, explicaremos qué es la violencia filio-parental y las distintas formas en las que se puede manifestar, incluyendo en este apartado las características que la componen a diferencia de otros tipos de violencia intrafamiliar y a continuación, expondremos tres teorías que a nivel general explican por qué estos jóvenes toman represalias contra sus padres. 
Posteriormente y en relación al desarrollo, nos centraremos en los sujetos protagonistas de esta modalidad de violencia, es decir, en los hijos y en los padres, así como en los factores sociales e individuales que llevan al hijo a cometer este tipo de conducta y los elementos que inhiben la falta de remordimiento o de culpa.

Una vez llegados a este punto del trabajo donde ya sabremos cómo se desata esta violencia en casa y qué es lo que sucede en el sujeto para acabar agrediendo a sus padres, abordaremos el término síndrome del emperador en relación al momento en el que la situación se ha desbordado por completo y hay que tomar medidas de forma urgente.

Posteriormente, hablaremos de las medidas a adoptar frente aquellos jóvenes agresores para que no lleguen a alcanzar la edad adulta bajo el mismo comportamiento y a continuación, daremos paso a la conclusión del trabajo donde expondremos las posibles formas de detectar el problema para así solucionarlo.

\subsection{Una realidad oculta. Repercusión y datos cuantitativos en España.}

Debido a que conocemos únicamente los casos en relación a las denuncias judiciales que interponen los padres a sus hijos, podemos decir que estamos ante una realidad oculta, ya que se conoce el fenómeno cuando el problema se ha desbordado, pero desconocemos los casos donde los padres deciden no denunciar y sin embargo también sufren este tipo de violencia.

En el periódico El País del 14 de septiembre de 2005, J.M. Lázaro ya relataba que la violencia doméstica ejercida de hijos a padres iba creciendo de forma "desmesurada". Se trata de delitos de amenaza ejercidos de forma reiterada en un período prolongado de tiempo y que en la mayoría de casos no da lugar a la denuncia por parte de los perjudicados, porque lo consideran como actos inevitables de rebeldía en la etapa de la adolescencia, o porque el sentimiento paternal les impide tomar medidas contra sus descendientes.

A continuación, vamos a hablar de datos cuantitativos que se han ido dando hasta el año 2016 debido a las denuncias interpuestas.

El Centro de Investigación en Criminología de la Universidad de Castilla-La Mancha elaboró una investigación sobre los menores maltratadores durante el período de 20012006, identificando a 146 sujetos con un total de 194 actuaciones. De los datos estudiados se desprende que, por cada 10.000 habitantes de 0 a 17 años, la tasa de hijos agresores es de $42,9 \%$. 
Además, el informe especial que presentó el Defensor del Menor de Andalucía (2014), destacaba sobre la violencia filio-parental en este territorio que se produjo un elevado incremento de sentencias a menores entre 14 y 17 años por violencia contra sus padres, de modo que las resoluciones aumentaron en 208 casos de 2007 a 2013, es decir, aproximadamente un $60 \%$.

Dicho informe, además relata que desde el año 2007 la Fiscalía General del Estado ha ido recogiendo la incidencia a nivel nacional. Según dicha institución, en 2008 se dieron 2.683 denuncias, 4.211 en 2009, 5.201 en 2010, 4.995 en 2011, 5.377 en 2012 , 4.659 en 2013 y 4.753 en 2014.

Según la Fundación Amigó (2018), en el año 2015 se alcanzaron 4.898 denuncias y en el año 2016 se observó un leve descenso del 11\% con 4.355. Tras analizar las diferentes memorias regionales de las Fiscalías de Menores de las distintas comunidades autónomas, es en Andalucía, la Comunidad Valenciana y Madrid donde se abren un mayor número de expedientes.

Dicho esto, en Andalucía se incoaron un total de 926 expedientes en el año 2015 y en el año 2016 la cifra ascendió a 1.083, habiendo entonces incrementado un 17\%.

En cuanto a la Comunidad Valenciana, en el año 2015 se conocieron 1.056 expedientes, los cuales correspondían 708 a Valencia, 311 a Alicante y 37 a Castellón. Sin embargo, en el año 2016 se produjo un descenso del 57\%, contando con 648 casos repartidos en 349 en Valencia, 219 en Alicante y 80 en Castellón.

Por último, en la Comunidad de Madrid en el año 2015 se recogieron 406 casos y en el año 2016 se dio un incremento del 37\%, pasando a ser un total de 558 casos.

Sin embargo, estos números puede que se encuentren muy por debajo de la realidad, porque muchos padres no llegan a denunciar a sus hijos por una serie de motivos que se desarrollarán a lo largo del texto.

Algo está sucediendo cuando las estadísticas mencionadas anteriormente crecen conforme van pasando los años, esto nos lleva a plantearnos si esta violencia hacia los ascendientes siempre ha existido o es un fenómeno nuevo que va creciendo con el paso del tiempo. Indudablemente siempre ha habido padres que han sido insultados o golpeados por sus descendientes, pero existen motivos para pensar que esta violencia ha ido creciendo debido a una serie de razones que se pueden abordar analizando al sujeto activo (adolescentes) en la sociedad actual y pasivo (padres).

Tal y como relatan Chinchilla, Gascó, Gracia y Otero (2005) en su informe especial del Boletín Oficial de las Cortes de Aragón, es en los años 90 cuando se descubre en 
España este nuevo tipo de violencia en jóvenes. Describiéndola como un tipo de violencia sensible debido a la alta carga emocional unida a la dependencia afectiva de los padres hacia sus hijos.

Si echamos la vista atrás, una de las razones sería el resurgir de otros tipos de violencia juvenil como bandas latinas, ultras de equipos de fútbol, skins... Grupos violentos que actúan en conjunto y cometen actos delictivos para defender o conseguir aquello que quieren.

Otra de las razones sería a consecuencia de las agresiones que se ven en televisión, prensa o cualquier medio de comunicación y que acaban normalizándose debido a la cotidianeidad con la que sucede. Dentro de estas agresiones que se transmiten por los medios, también se encuentra el acoso escolar llamado bullying, un tipo de violencia que se ejerce de forma prolongada por un grupo de alumnos sobre otros. Aquellos niños o adolescentes que ejercen el llamado bullying contra otros compañeros aprenden que la dominación que ejercen tiene beneficios, por lo que prueban a aplicarlo en otros ámbitos, en este caso en el ámbito familiar.

En cuanto a los padres hay que hacerse una pregunta, ¿a qué madre o padre le gusta denunciar a su hijo o recurrir a los profesionales? La dificultad de los padres tanto para recurrir a la ayuda de un profesional como para interponer una denuncia conlleva que los hijos piensen que sus padres son incapaces de tomar medidas en su contra.

Esta dificultad quizá se deba a que los padres no quieren reconocer que son víctimas de sus propios hijos, lo que significaría que su hijo adopta comportamientos aberrantes en su contra debido a su fracaso como educadores.

Pero realmente el problema no radica únicamente en el fracaso de los padres a la hora de educar. Existen hijos que son indisciplinados y violentos aun teniendo padres que han llevado a cabo una buena educación, siendo atentos, entregados y recurriendo a la asistencia o ayuda necesaria cuando lo han considerado.

Es cierto, no obstante, que la probabilidad de que el hijo agreda a sus padres es menor en comparación con aquellos que han crecido en un ambiente hostil, donde el uso de la violencia entre los miembros de la familia ha sido algo cotidiano, o aquellos que han estado desatendidos por parte de sus padres.

Una última razón por la que actualmente se dan más casos de violencia filio-parental, es que a día de hoy y en relación con los niños y adolescentes, se ha retrasado el momento en el que tienen que contribuir dentro de la familia, por lo que el nivel de responsabilidad es menor. Esto es consecuencia de que la formación académica actual abarca un abanico mucho más amplio de posibilidades a la hora de elegir y el tiempo de dedicación que requiere dicha formación. 
Un ejemplo de violencia filio-parental donde la mayoría de las veces los padres no denunciaban a sus hijos se vio muy bien reflejado en un programa español de televisión llamado "Hermano Mayor". Con millones de espectadores donde se podía ver la realidad de la violencia filio-parental, al ver a familias desbordadas por culpa de la agresividad de los hijos. El presentador de dicho programa era Pedro García Aguado, un ex deportista de élite, que fue politoxicómano y que actualmente trabaja en un centro de rehabilitación de personas drogodependientes en Barcelona. El presentador convivía durante un tiempo en el hogar donde se desarrollaba la violencia filio-parental para así plantear soluciones al respecto.

Con la aparición de este programa que ponía de manifiesto el comportamiento de los hijos contra los padres se consiguió un gran éxito de audiencia. El suceso lleva a pensar que la sociedad acude a un programa de televisión en busca de soluciones, y además, suponer que a estas familias les ha fallado su método a la hora de educar y buscan verse reflejados en otra familia con la misma situación para así poder obtener algún tipo de respuesta que les pueda servir como ayuda, es decir, cómo prevenir dichas situaciones, una explicación al porqué de ese comportamiento hostil en los hijos y la posible solución una vez desatado el problema.

Nos encontramos ante una realidad distinta a años atrás, una realidad oculta que únicamente se manifiesta cuando debido a su gravedad, los padres deciden dar el paso de dejar que la justicia actúe en contra de sus hijos.

\section{Violencia filio-parental.}

\subsection{Definición, tipos de violencia filio-parental y características.}

La agresividad es algo con lo que nacemos, algo innato y natural. Forma parte del hombre como algo necesario a la hora se resolver ciertas situaciones. Esta condición no siempre es negativa, una persona puede manifestar agresividad a la hora de realizar un ejercicio físico para conseguir una determinada marca de tiempo, por lo que estaríamos ante una situación positiva de agresividad, en cambio, la violencia es un comportamiento negativo que se aprende desde que nacemos y que se va construyendo de una forma $\mathrm{u}$ otra, dependiendo de los diferentes factores que rodean al individuo.

Tal y como anota Abadías Selma (2015, p. 42), "las semillas de la violencia se siembran en los primeros años de la vida, se cultivan y se desarrollan durante la infancia y comienzan a dar sus frutos malignos en la adolescencia". 
En cuanto a la violencia filio-parental se encuentra dentro del contexto familiar. En general, cuando se habla de familia y hogar lo asociamos a la tranquilidad de estar con personas que te quieren, te cuidan, te respetan, etc. También a la protección, seguridad y armonía que aporta el tener un espacio donde te aíslas de lo que sucede en el exterior. Ahora bien, la violencia en el hogar existe, este tipo de violencia intrafamiliar es un fenómeno real del que no se habla tan a menudo como de otros tipos de violencia doméstica.

Basándonos en la idea general sobre la violencia filio-parental de Torres Ayala (2018), es una conducta violenta que se ejerce de manera reiterada por parte del hijo, normalmente adolescente, contra sus ascendientes con plena intención y consciencia. Esta conducta se lleva a cabo durante un período largo de tiempo y tiene como finalidad la sumisión de los padres frente a los hijos, para así conseguir todo cuanto deseen sin obtener un "no" por respuesta.

En la mayoría de los casos los padres afirman no sentirse amenazados ni coaccionados por los hijos, defendiendo así la postura autoritaria que estos adoptan. Se crea una lucha interna de forma inconsciente entre el amor y el odio. Aparentemente, frente a terceros no presentan ninguna característica por las que puedan ser identificados como víctimas de maltrato filio-parental, a pesar de esta invisibilidad, el perjuicio y los daños existen.

Se pueden ejercer distintos tipos de violencia, pero en este caso, Alfredo Abadías Selma (2015) clasifica las diferentes modalidades en tres grandes tipos: violencia física, psicológica y económica, siendo las más comunes en este tipo de violencia.

En primer lugar, la violencia física se caracteriza por una serie de acciones que van dirigidas a atentar contra la integridad corporal de la persona y se puede llevar a cabo tanto por medio del cuerpo como de objetos.

Por otro lado, la violencia psicológica mediante el lenguaje verbal y no verbal, atacando a nivel emocional a sus progenitores. El agresor quiere intimidar a la víctima hasta el punto de anularla y tenerla a su plena disposición. Atenta contra los sentimientos y la afectividad de los padres, llevando a un sentimiento de culpa, frustración y trauma permanente. En este caso, al ser el hijo el agresor, conoce las palabras exactas que debe usar para dañar emocionalmente e instaurar el terror en sus padres. Por ejemplo, amenazando con quitarse la vida, autolesionarse culpando a los padres de algún mal, desprecios, gestos de indiferencia ante problemas graves en la familia, etc.

Normalmente estos dos tipos suelen ir unidos, puesto que de la violencia física nace el daño psicológico o emocional, debido al sentimiento de humillación, ofensa de orgullo y honor de la persona. 
Por último, la violencia económica. Este tipo limita el ingreso o el ahorro que puedan tener los padres al endeudarlos mediante las compras abusivas con sus respectivas tarjetas de crédito o la destrucción de objetos. También el robo de dinero y joyas para posteriormente venderlas y conseguir aquello que quieren.

El fin con el que los hijos realizan estas acciones es el de obtener el dominio, poder y control absoluto sobre las víctimas para vivir como quieren y poder conseguir cuanto deseen. No siempre se desarrollan a la vez dichas conductas, aunque la mayoría de veces van ligadas, ya que la violencia física conduce a la violencia psicológica, debido al pánico causado en las víctimas. $Y$ para hacer frente a la violencia económica, se pueden desatar episodios violentos por la negación o el impedimento a la hora de cometer el robo.

Además de los tipos de violencia filio-parental que hemos visto, existen tres características comunes en este tipo de violencia:

La primera es la difícil detección. Se desarrolla dentro del ámbito familiar, por lo que el alcance del conocimiento externo de la situación es más bien inexistente. Para que personas ajenas al núcleo se percatasen del problema, este se tendría que haber desbordado debido a la gravedad. Aparte de la dificultad para conocer el problema por el lugar en el que se desarrolla, muchos de estos comportamientos se entienden como normales dentro de una familia, confundiéndose así con disputas habituales entre padres e hijos.

Otra de las características sería la insensibilización, ya que actualmente vivimos en una sociedad en la que estamos expuestos la gran parte del día a la televisión, radio, internet, redes sociales, videojuegos, etc. Esto lleva a que las situaciones violentas que se generan en estos medios se normalicen y acepten como algo cotidiano. A consecuencia de esto, no se da la importancia suficiente a las escenas violentas que podamos presenciar, puesto que lo justificamos como algo que se ve o escucha todos los días.

Además de lo mencionado anteriormente sobre la difícil detección y la insensibilización, existe otra característica que sería el encubrimiento: la propia familia encubre al agresor por miedo a que se genere una desestabilización familiar o se dé una ruptura de la unidad. Este temor también va ligado al "qué dirán" y al miedo de lo que piense la sociedad acerca de ti y de tus seres queridos.

Una vez explicada la violencia filio-parental, los tipos de conducta a los que da lugar y los puntos que la caracterizan, vamos a desarrollar los diferentes modelos explicativos que a lo largo del estudio de este fenómeno han tenido especial trascendencia. 


\subsection{Modelos teóricos}

Existen dos tipos de factores que influyen en el individuo y desatan el comportamiento violento, hablamos del factor social e individual. Los modelos teóricos que a continuación vamos a explicar facilitan la comprensión del comportamiento hostil en cuanto al factor social. En cambio, los factores individuales no proporcionan una explicación general sobre la violencia, ya que cada individuo de forma aislada tiene unas condiciones y características diferentes.

\subsubsection{Teoría del aprendizaje social}

Esta teoría se fundamenta en la exposición a un ambiente violento desde el nacimiento, es decir, defiende que las personas que están expuestas a cualquier tipo de violencia desde que nacen tienen una mayor posibilidad de cometer actos violentos que aquellos que nunca, o raras veces, han presenciado algún acto hostil a lo largo de su vida. Por ejemplo, los niños que hayan crecido como testigos de malos tratos entre sus padres o como víctimas directas, en el futuro posiblemente serán personas que emplearán la violencia de forma cotidiana. Además, esta teoría también se basa en el posible aprendizaje de conductas violentas mediante las nuevas tecnologías. Los niños que hacen uso de internet, videojuegos, televisión, etc., aprenderán este tipo de comportamientos que irán desarrollando hasta la edad adulta caracterizándolos como personas violentas.

\subsubsection{Teoría del intercambio social}

Según Peter Blau (1964), esta teoría se fundamenta en la recompensa que recibirá el individuo dependiendo del comportamiento que adopte, por ejemplo, alguien le pide que le haga un favor y si acepta, es porque espera obtener algún beneficio a cambio. Si el beneficio lo obtiene tal y como esperaba, se sentirá satisfecho, por lo que seguirá teniendo buena relación con esa persona, sin embargo, si tras realizar el favor no existe la reciprocidad que esperaba, siendo este el motivo por el que había aceptado, se desatará un comportamiento de ira y violencia que interrumpirá la buena relación con esa persona.

Por lo tanto, cuanto mayor sea la recompensa o la reciprocidad, mejor será la relación con esa persona y, por el contrario, cuanto menor sea la recompensa, peor será la relación con dicha persona debido al comportamiento peligroso y hostil que desarrollará, es decir, si el individuo recibe algún perjuicio por su parte, el contrario recibirá daños por la suya, dándose así por satisfecho. 
Esta teoría da por finalizado el comportamiento violento en el momento en que el sujeto considere saldada la deuda.

\subsubsection{Teoría general de la presión}

Esta teoría desarrollada por Agnew (1992) defiende que la conducta violenta que adopta el individuo tiene relación con la ira y frustración que se genera al recibir un trato de inferioridad por parte de la sociedad, Agnew habla de tres tipos de presiones.

La primera de ellas es la incapacidad de conseguir objetivos que están valorados de forma positiva en la sociedad. A consecuencia de ello, los individuos actúan de forma ilegítima para poder conseguir dicho fin.

El segundo tipo de presión es consecuencia de las sensaciones negativas. El ser o haber sido víctima de malos tratos crea la necesidad de consumar mediante actos hostiles un tipo de venganza y así saciar el estrés que se genera o generó en el tiempo como víctima.

Por último, la presión que se genera tras haber perdido o estar a punto de perder un estímulo positivo, como puede ser la pérdida de un ser querido. En este caso, el individuo sustituye la pérdida mediante recompensas obtenidas de forma ilícita.

La respuesta a todos estos tipos de presión sería la ira. La ira aumentaría la agresividad en el comportamiento y este desembocaría en lo violento o criminal.

Estos tres tipos de modelos explicativos van ligados a factores externos. Situaciones y vivencias que se desarrollan a lo largo de la vida del sujeto y que sirven de aprendizaje durante el desarrollo, influyendo también en el modo en que gestionarán o resolverán conflictos internos. Como hemos comentado anteriormente, dependerá además de una serie de factores individuales, que, junto a los sociales, hacen que un individuo sea más o menos violento.

\section{Las causas de la violencia filio-parental}

Actualmente vivimos en una sociedad consumista, la necesidad de obtener aquello que se quiere no conoce límites ni restricciones, sino que más bien lleva a la búsqueda del placer inmediato de aquello que deseamos sin ser capaces de posponer dicha necesidad. Los jóvenes que no conocen las limitaciones, el sufrimiento o los fracasos, se convierten en sujetos poco tolerantes y que se frustran con facilidad, lo que conlleva reacciones violentas cuando no obtienen lo que desean, sea cual fuere el ámbito en el que 
se desarrolle. La suma de dicha influencia social con los elementos desencadenantes y potenciadores y con los factores de riesgo sociales e individuales que a continuación explicaremos, será lo que dé lugar a la violencia filio-parental.

\subsection{Elementos desencadenantes y potenciadores}

En este apartado explicaremos lo que Según Berkowitz (1990, pp. 494-503) son elementos desencadenantes y potenciadores que influyen en el individuo a la hora de cometer actos violentos en contra de sus padres.

En primer lugar, hablaremos del temperamento como la disposición previa a un determinado tipo de respuesta. Existe una estrecha relación entre el temperamento y los problemas conductuales y emocionales. El tipo de temperamento lo encontramos en la mayor o menor irritabilidad que puede presentar un sujeto, ya que la irritabilidad precede a la ira, agresión y violencia. Este temperamento negativo se asocia con una alta necesidad de búsqueda de sensaciones, para así poder transformar la negatividad en positividad.

En segundo lugar, encontramos la personalidad, un rasgo que caracteriza al sujeto a la hora de comportarse de una determinada manera. Aquél que tenga una personalidad extravertida, es decir, que tenga interés por lo externo, la sociedad, el reconocimiento social etc., que además suela tender a la búsqueda insaciable de sensaciones, caracterizada por una baja percepción del riesgo o daño que puede ocasionar y poca tolerancia a no recibir de forma inmediata la recompensa esperada. Este tipo de jóvenes suele ser más propenso a cometer conductas violentas.

Otro de los elementos previos que influyen en la conducta violenta del adolescente es la impulsividad. El modo de responder ante unos estímulos de forma rápida, sin realizar una reflexión previa lo cual suele llevar a cometer errores. Los sujetos impulsivos se caracterizan principalmente por la exteriorización de ideas y pensamientos y por no poder controlar sus deseos. Buscan de manera insaciable nuevas sensaciones, se aburren con facilidad y tienen una visión de la realidad distorsionada. La impulsividad es uno de los factores que más influyen en la conducta violenta, esto se debe a la incapacidad de espera y reflexión ante cualquier situación que requiera control y tiempo a la hora de actuar.

En cuarto lugar, encontramos la depresión. Muchos adolescentes deprimidos expresan este sentimiento a través de conductas violentas y de oposición. Puede manifestarse con violencia hacia uno mismo como la autolesión, el consumo de drogas a modo 
de evasión de la realidad que tanto malestar les crea, conductas hostiles frente a sus padres por no sentirse entendidos y culpabilizando a estos de dicho malestar, e incluso amenazando con el suicidio. También la depresión va acompañada de la baja autoestima y desconfianza hacia terceras personas. Esta baja autoestima en adolescentes hace que cuando adoptan una conducta violenta o que no está aprobada por la sociedad no tengan miedo, al considerar que no tienen nada que perder. Además, los adolescentes integrantes de un grupo igual de violento que ellos, en los cuales se genera un clima de aceptación sobre estas conductas, a diferencia de la realidad, donde encuentran carencias. La pertenencia a este grupo de iguales conlleva a sentir reforzadas estas conductas violentas produciéndoles así, un incremento en la autoestima.

El sexo es otro de los elementos que influyen en la conducta violenta, predomina en el sexo masculino. Los hombres a diferencia de las mujeres desatan generalmente estas conductas de forma física, es decir, atentando contra la integridad de bienes o personas. Una de las explicaciones sería el alto nivel de testosterona en comparación a las mujeres y de la educación más severa que suelen recibir.

En sexto lugar hablaremos de la edad. En relación a la violencia filio-parental, es en la adolescencia cuando más se desarrolla este fenómeno, pero el inicio corresponde a las etapas anteriores como desencadenante de dicha conducta, es importante darse cuenta en los primeros años de vida de los síntomas que pueda presentar un sujeto en cuanto a conductas violentas, para así poder solucionarlo, ya que la violencia en la primera infancia es uno de los mejores predictores de las conductas futuras y del nivel que adquirirá si no se toman medidas o soluciones al respecto.

El último elemento es la baja autoeficacia. La autoeficacia es una característica personal mediante la cual el sujeto es capaz de realizar sus propósitos y conseguir con ello la aprobación social y la recompensa por parte de terceros. Las personas que tienen una baja autoeficacia se frustran y dicha frustración les conlleva a la ira y a la agresividad.

\subsection{Factores sociales.}

En cuanto a la influencia de los factores sociales, según Garrido Genovés (2019, pp. 33-38) existen una serie de causas que influyen en la formación del joven agresor. Estas causas son cinco: no se educa la conciencia, familias monoparentales, estrés por parte de los padres, hijos que no adoptan roles responsables y una sociedad consumista. 
La conciencia no se educa. Tal y como dice Garrido Genovés (2019, p. 33-34), es algo que se construye en el mundo del afecto, de los sentimientos. Nadie nos puede educar a la hora de sentir compasión, amor, tristeza o rabia. Son estos sentimientos los que nos dicen que podemos hacer y que no podemos hacer. Digamos que es una guía que nos orienta a la hora de actuar y de conocer la responsabilidad a la que nos pueden llevar nuestros actos.

Entonces, ¿qué pasa cuando nuestra conciencia no se ha desarrollado conforme a unos criterios morales que nos harán de guía diferenciando lo que está bien y lo que no? Lo que ocurrirá en este caso será que el individuo que lo padezca interpretará la vida como una competición donde tiene que ganar, tiene que conseguir aquello que desee sin importarle el perjudicar a otros. Esto se puede desarrollar mediante violencia verbal o física principalmente hacia los familiares, para así poder controlar y dirigir a su antojo sus vidas.

Abordando el punto de las familias monoparentales, en primer lugar, hacemos referencia a madres que educan solas. Como hemos comentado anteriormente, uno de los factores desencadenantes del comportamiento violento en los adolescentes, son las separaciones matrimoniales. En este caso y previamente a la separación, los conflictos entre pareja que presencian los hijos crean entornos desestabilizantes y tensiones que pueden llegar a desbordarse. Cuando estos conflictos acaban en la disolución del matrimonio, la madre, que es por norma general la que se queda a los hijos, es la que sufre actitudes hostiles por no tener el apoyo de la pareja. Cualquier sentimiento de ira y frustración del hijo será pagado por ella.

En cuanto a los padres, a veces se hallan sometidos a mucho estrés. Este estrés se debe a que muchas familias viven situaciones donde existen dificultades económicas a la hora de llegar a fin de mes. El estrés que generan estas situaciones hace que se den episodios agresivos y violentos.

La cuarta causa, vivir en una sociedad consumista, enseña desde una temprana edad a que todo lo que se quiere se tiene que conseguir lo más rápido posible. Comprar lo que se quiere en ese momento sin pensar en si se necesita. En relación a la violencia filio-parental, educar a los hijos para que consuman de forma racional y siendo responsables, genera enfrentamientos, teniendo que hacer frente a la situación de forma cotidiana si quieren educar a sus hijos a consumir "con cabeza".

La última causa hace referencia a la falta de responsabilidad por parte de los hijos. Esto es debido a una sobreprotección que tiene como consecuencia una madurez tardía. La vida presenta una serie de problemas, ya sean familiares o personales, y en 
este caso, son los padres los que resuelven los de sus hijos. Esto es un error, puesto que lo correcto sería enseñar a manejar estas situaciones para poder solventarlas en un futuro sin necesidad de recurrir a ellos. Existe un dicho que define muy bien esta explicación: "dale a tu hijo dos cosas imperturbables: las raíces y las alas", lo que quiere decir, educar a tus hijos a enfrentarse a las adversidades para que luego estos se enfrenten solos.

Además de los cinco factores considerados anteriormente, la importancia de la familia en relación con la violencia filio-parental también es otro factor que radica sobre todo en los diferentes modelos existentes a la hora de educar a los hijos. Controlar a estos desde pequeños y supervisar sus comportamientos es un factor que marcará su educación, pudiendo ser decisivo para evitar conductas de violencia filio-parental. Tanto un control severo como un control casi ausente son negativos para el hijo. El tipo de educación se tendrá que adaptar de forma progresiva al hijo respecto a su madurez, para así llegar a acuerdos donde las dos partes estén conformes y no dar pie a posibles disputas.

El punto de conflicto entre lo que quieren los hijos y lo que permiten los padres marca el principio de la violencia filio-parental en lo que respecta al factor de la responsabilidad familiar, es decir, existen padres que al sentirse agobiados y desbordados por la insistencia de los hijos a la hora de conseguir lo que quieren, deciden desistir y consienten, esto llevará a una evolución negativa de los hijos, que aprovecharán el desistimiento de los padres y cada vez querrán más.

A continuación, explicaremos una serie de estilos educativos que podrían ser complementarios a los factores sociales comentados anteriormente, y que pueden impulsan consecuencias negativas en el desarrollo de los hijos cara al futuro y que darán lugar a la violencia filio-parental. En la doctrina de nuestro país, encontramos a Ibabe, Jaureguízar y Díaz (2007, pp. 26-27) que clasifican tres estilos educativos como favorecedores de la violencia filio-parental.

En primer lugar, nos hablan de las familias que tienen como estilo educativo el permisivo-liberal, sobreprotector y sin normas conscientes. Se trata de una educación que se caracteriza por el exceso de protección y la incapacidad de mostrarse autoritarios frente a los hijos, lo que lleva a ser excesivamente permisivos con todo aquello que demanden. Los adolescentes que son educados con este estilo tienen poca tolerancia a la frustración, puesto que los deseos que demandan son satisfechos de forma inmediata y sin esfuerzo previo para conseguirlo. A lo largo del tiempo, los padres al ver que la situación se ha desbordado se contradicen a la hora de establecer normas, lo que conlleva que los hijos no tengan una serie de límites fijados de forma clara. Finalmente, 
cuando los padres acaban renunciando a su papel de autoridad, se ven incapaces de detener las conductas violentas que los hijos adoptan cuando estos intentan poner algún limite.

En segundo lugar, establecen el estilo autoritario con violencia intrafamiliar. La característica fundamental de este modelo es la rigidez y agresividad a la hora de interactuar dentro de la familia. Se ensalza la violencia a la hora de conseguir un objetivo y los castigos que se interponen a los hijos suelen ser mediante rechazos, insultos o violencia física. Esta forma de recibir castigos propiciará que cuando alcancen la adolescencia se rebelen contra los padres.

El tercer y último estilo es el negligente-ausente. A consecuencia de que los padres sean incapaces de asumir el rol como educadores, los hijos toman las riendas. Hablamos de familias donde prima el estrés y debido a ello, los adultos descuidan el rol que deben de adoptar frente a sus hijos y las responsabilidades que les deben otorgar. El estrés da pie al conflicto dentro del matrimonio, lo que involucra al hijo en el problema incurriendo este a la violencia como medio de rechazo ante lo que está viviendo y la situación de tener que adoptar un rol que no le corresponde.

La unión de uno de estos tres tipos de estilos educativos junto a los demás factores sociales que hemos comentado, son los que generarán en lo que respecta a los factores sociales que un individuo acabe adoptando conductas autoritarias y violentas contra sus padres. Entendiendo así que existen distintos motivos que desatan este comportamiento. Es decir, un cuadro integrado por diversas cuestiones que dan lugar a la violencia filio-parental.

\subsubsection{Intercambio de rol entre padres e hijos}

Además de los factores sociales anteriores, en este apartado cabe destacar el intercambio de roles que se genera entre padres e hijos. Garrido Genovés (2019, p. 34) tiene un argumento claro ante el porqué de dicho intercambio entre las partes que lo divide en dos. El primero trata sobre la filosofía educativa de los padres y el segundo sobre la sociedad.

Por una parte, el avance de la economía y de la tecnología ha incrementado la comodidad y seguridad en la sociedad, esto ha creado un modo de vivir consumista donde tenemos que obtener y satisfacer nuestros deseos materiales de forma inmediata. A este término Garrido Genovés (2019, pp. 34-35) lo llama hedonismo como filosofía de consumo vital. Si los padres adoptan este comportamiento de querer un bien y conse- 
guirlo de forma inmediata, los hijos aprenderán de ello y estarán acostumbrados al consumismo, sin haber aprendido a controlarse ni a desarrollar una serie de normas que los haga responsables, esto desatará comportamientos tiranos hacia los padres cuando no satisfagan esa necesidad que les crea lo material.

Por otro lado, en cuanto a la sociedad, hay que moverse para llegar a fin de mes, puesto que no solo basta con cubrir las necesidades básicas, sino también las necesidades de querer poseer una serie de productos que no son imprescindibles para vivir. Esta lucha para poder hacer frente a los gastos lleva a que los padres, como trabajadores, flaqueen a la hora de educar debido a la dificultad de conciliar la vida familiar con la vida laboral.

La problemática abordada en el párrafo anterior da lugar a una gran cantidad de divorcios, debido a que los matrimonios no saben cómo hacer frente a esta presión. Una vez producido el divorcio, los roles como educadores se van difuminando y los niños acaban tomando las riendas aprovechando el conflicto familiar, aprovechándose del modelo monoparental, para poder conseguir aquello que deseen

\subsection{Factores individuales}

Una vez comentados los elementos potenciadores y desencadenantes y los factores de riesgo sociales que dan lugar a la conducta violenta, vamos a dar paso a los factores individuales y a una serie de características que comparten todos ellos que hacen posible la detección.

Por un lado, empezaremos hablando de los factores individuales relacionados con las enfermedades mentales. Las enfermedades mentales se caracterizan por una serie de trastornos que afectan a la vida de la persona debido a la conducta que adoptan de manera independiente a su voluntad. Las causas que dan lugar a estos trastornos relacionados con la violencia filio-parental se pueden dar en lo social, psicológico y biológico.

Benedicto Duque (2015, pp. 483-488) hacía hincapié en la relación entre cuadros psicopatológicos y conductas de la violencia filio-parental. Este autor afirmaba que la mayoría de los adolescentes que habían estado internados cumpliendo una medida judicial por delitos de maltrato contra sus padres, habían estado previamente tratados por servicios de salud mental cuyo diagnóstico recogía alguna psicopatología. 
Los tipos de trastorno que se dan en mayor porcentaje entre los adolescentes que ejercen maltrato hacia sus padres son, según Benedicto Duque (2015, pp.483-488) y referidos a adolescentes ingresados en el centro de internamiento Teresa de Calcuta: El Trastorno de Conducta con un 20\%, el Trastorno Disocial con un 17,7\% y Trastorno por Déficit de Atención e Hiperactividad con un 15,5\%.

Una vez mencionados los tres tipos de trastornos predominantes en estos sujetos daremos paso a su explicación.

El Trastorno de Conducta consiste en la repetición de un patrón de comportamientos a lo largo del tiempo en los que no se respetan las normas, las leyes o los derechos básicos para una convivencia adecuada. Consistiría, por ejemplo, en cometer de forma reiterada robos a los padres, agredir a animales e incluso a personas, o atentar contra la propiedad ya sea propia o ajena. Existen una serie de síntomas de fácil detección en adolescentes que sufren este trastorno de la conducta, hablamos de ausencias en el colegio, irresponsabilidad a la hora de hacer deberes y de aprobar exámenes, mentiras a los padres, fugas del hogar cuando se les imponen unas normas y horarios, responsabilizar de todo al a familia, baja tolerancia a los castigos, etc.

En cuanto al Trastorno Disocial, igual que el Trastorno de Conducta, se sigue el mismo patrón de violar los derechos de los demás y pasar por alto cualquier norma por la que se rija la sociedad. Las características más evidentes que lo diferencian son entre otras, la impulsividad sin ningún tipo de control, la frialdad al cometer actos crueles y vandálicos que puedan dañar a un tercero e incluso a sus propios padres, la necesidad de satisfacer sus deseos de forma inmediata, el narcisismo, problemas para aprender cualquier tipo de norma, etc.

Por último, el Trastorno por Déficit de Atención conocido como TDHA. Este trastorno se caracteriza por la dificultad de prestar atención y controlar comportamientos inadecuados, por ejemplo, al ser sujetos que adoptan malos comportamientos, suelen pelear con todo aquel que les rodea. Al ser un problema para la sociedad en cualquier ámbito, se convierten en personas aisladas que probablemente acaben relacionándose con amistades que adopten el mismo comportamiento. La incomprensión y los castigos reiterados de los padres provocan que este tipo de sujetos actúen de forma hostil para defenderse y llamar la atención.

A estos tres trastornos predominantes en adolescentes que ejercen violencia contra sus padres, a menudo se les asocia el abuso de sustancias tóxicas. Por un lado, este abuso se considera un factor de riesgo independientemente de que se sufra alguno de los trastornos anteriormente comentados y por otro, se observa que los adolescentes 
que consumen alcohol y otras drogas presentan diagnósticos de estos tres tipos de trastorno agravando así la detección y el tratamiento.

Como acabamos de comentar, encontramos también como un factor de riesgo individual el consumo de drogas. Esto puede actuar como predictor de la violencia filioparental o como desencadenante, por lo que o es causa, cometer actos violentos como robar a tus padres para así poder comprar drogas, o es consecuencia, llevar a cabo una conducta violenta contra ellos debido a los efectos de estas. En el ámbito de la violencia filio-parental, predomina la primera opción. Los hijos adoptan un temperamento hostil y violento en contra de sus padres para obtener dinero y poder hacerse con la droga que quieren en el momento que quieren.

Actualmente son el alcohol y el cannabis las drogas más comunes en adolescentes. Son dos tipos que se pueden obtener fácilmente y que a la larga está demostrado que pueden llegar a causar una diversidad de trastornos. Si no en la familia, en el colegio desde la infancia se habla de las drogas. De qué son, de los efectos, de las consecuencias a las que pueden dar lugar y aun así los jóvenes las consumen, ¿por qué? Debido a los efectos esperados por estos adolescentes. Hablamos de efectos positivos que se producen de forma instantánea, que los evade de la realidad y los aísla de cualquier tipo de problema que les perturbe.

A modo de conclusión en cuanto a los factores individuales, la existencia de trastornos y el consumo de sustancias tóxicas, son factores que caracterizan al sujeto que desarrolla conductas de violencia filio-parental.

\subsubsection{De puertas para afuera. Características de los agresores.}

Además de los factores individuales que acabamos de comentar, encontramos una serie de rasgos que caracterizan a estos individuos y que son de fácil detección, puesto que se pueden apreciar en el sujeto en su día a día, ya sea en el colegio, en el círculo de iguales, etc.

\subsubsection{Narcisismo y rasgos psicopáticos.}

Sabiendo que la violencia filio-parental es un fenómeno que se desarrolla dentro del hogar, vamos a explicar cuál es la apariencia y el comportamiento que adoptan este tipo de agresores cuando se encuentran fuera de este. 
Un joven que agrede a sus padres para conseguir aquello que desea, que no tiene remordimiento alguno por ningún acto hostil de los que lleva a cabo, ¿qué comportamiento adopta con gente que no es de su confianza?

Vivimos en una sociedad donde predomina el deseo material y el poder conseguir lo más rápido posible dicho deseo, una sociedad cargada de elementos narcisistas, donde sobre todo los adolescentes están pendientes de su placer egocéntrico, de sus éxitos, de destacar frente a los demás, de que sean admirados y halagados constantemente, etc. Es en esta etapa cuando el adolescente empieza a definir su identidad y a guiarse hacia el futuro, por lo que tal y como anotan Larraín y Monserrat Arieta (2010, pp.174189), es el momento donde existe el riesgo de que aparezca el narcisismo en el adolescente, la etapa donde el adolescente se quedará atrapado en el amor por sí mismo.

Los narcisistas a pesar de pensar únicamente en su persona pueden sentir las emociones positivas y negativas del mismo modo y con la misma identidad que las demás personas, sin embargo, si ha existido la ausencia de apego y empatía durante su infancia, se pueden caracterizar por la incapacidad de entender lo que otra gente está sintiendo. Por lo tanto, si recabamos la información expuesta sobre los jóvenes violentos a lo largo del trabajo, los clasificaremos como personas narcisistas incapaces de entender el sufrimiento de terceros y que además pueden padecer algún tipo de enfermedad mental.

Estamos ante una serie de personas que de forma permanente entran en conflicto con su entorno social, cometiendo actos peligrosos a la hora de conseguir la satisfacción inmediata de sus deseos, Aguilar Cárceles (2017, pp. 5-10) define a las personas que padecen estos rasgos como seres sin sentimientos ni complejos, incapaces de aprender aun imponiéndoles una pena severa e integrándolos en la sociedad. Son personas inestables, inconformistas, impulsivas y fácilmente irritables, les importa únicamente su yo, es decir, son egocéntricos y narcisistas.

Los términos egocentrismo y narcisismo forman parte de algunos de los rasgos psicopáticos más relevantes, por lo que podríamos estar ante sujetos que padezcan dichos rasgos junto a los trastornos mencionados anteriormente. Sin embargo, existe una serie de diferencias entre la psicopatía y el trastorno antisocial que hace posible asociar una, otra u ambas conductas a un sujeto. Según Luengo y Carrillo (1995, pp. 615-650), cuando lo que prevalece en el sujeto es realizar una serie de conductas delictivas y en contra de las normas sociales, hablamos de trastorno antisocial, donde existe una variedad de delincuentes no psicópatas que entran en este grupo. En cambio, los sujetos con rasgos psicopáticos son capaces de desarrollarse dentro del buen funcionamiento 
de un grupo, fingiendo sentimientos de lealtad o afecto, prevaleciendo en ellos una serie de características y conductas de su personalidad, por lo que, a modo de resumen, diremos que la diferencia entre el trastorno antisocial y la psicopatía estriba en la forma de atentar contra la sociedad y la personalidad que caracteriza a uno.

Sin embargo, puede darse una variable que dificulta la apreciación a la hora de identificar si un sujeto padece rasgos psicopáticos a través de una conducta antisocial. Hablamos entonces del psicópata integrado, estos sujetos pasan desapercibidos entre la multitud debido a la capacidad que tienen de integrarse, se muestran personas agradables y encantadoras y tienen facilidad a la hora de conquistar a través del halago.

En relación a los adolescentes que no presentan esta dificultad y que agreden a sus padres, diremos que al adoptar tanto dentro como fuera de casa el mismo tipo de comportamiento violento y antisocial, será de fácil detección, pero en relación a los adolescentes integrados con rasgos psicopáticos, dentro de casa, se comportarán de forma violenta y fuera de ella, todo lo contrario, es decir, siendo simpáticos y encantadores, relacionándose con cualquier grupo de dónde sacará algún tipo de interés propio y por ello se verá dificultada la detección de dichos rasgos.

Según Hare (2003) el 25\% de los adolescentes que presentan un trastorno antisocial cumplen también con rasgos psicopáticos y el $90 \%$ de los psicópatas cumplen con las características del trastorno antisocial. En relación a lo explicado anteriormente y a los adolescentes que atentan contra sus padres, sabemos que la gran mayoría padecen este tipo de trastorno, sin embargo, no se darán como norma general las conductas psicopáticas.

\subsubsection{Egoísmo}

Según Garrido Genovés (2019, p. 43) las personas en general somos egoístas por naturaleza, cuando realizamos alguna labor por los demás buscamos beneficio propio. El egoísmo se puede manifestar de diversas formas, por ejemplo, el querer que tu pareja se adapte a tus deseos sin intentar que sea algo mutuo, el hacerle un favor a alguien pensando en que a la larga te lo tendrá que devolver, e incluso comportamientos altruistas como una gran donación económica que esconden el deseo de aumentar su reconocimiento y prestigio social.

Muchos de los actos egoístas pueden vulnerar prohibiciones, hablamos por ejemplo de aquellas personas que estafan a colectivos vulnerables (ancianos, personas enfermas, etc.) o personas que hacen uso de la violencia para cometer un robo. Cuando se 
alcanza dicho nivel de comportamiento prohibido, existen leyes que lo castigan. Gracias a esto ponemos freno al impulso de vulnerar los derechos de los demás pensando únicamente en uno mismo, puesto que al ser racionales nos abstendremos de infringir las normas y ser castigados, ya que esto puede sobrepasar al placer de cometer un acto egoísta y prohibido.

En cambio, si el joven agresor desde el nacimiento no desarrolla la conciencia, no sabrá distinguir entre lo que está bien y lo que está mal y, por tanto, el egoísmo se convertirá en algo habitual, donde el comportamiento que adopte será únicamente en su beneficio sin ayudar a los demás. Hablamos entonces de sujetos que no establecen vínculos emocionales o afectivos de ningún tipo, con lo cual les costará sentir tanto emociones positivas como negativas frente a estímulos externos.

Las personas establecemos vínculos debido a la reciprocidad y conexión que sentimos los unos con los otros, aquellos que no tienen conciencia ni sentimientos morales fracasarán a lo largo de su vida a la hora de establecer esta serie de vínculos, sin embargo, sí que estarán preparados para humillar, hacer daño o manipular a los demás.

A modo de conclusión, diremos que este tipo de adolescentes son personas narcisistas y egoístas, solo piensan en su persona y en poder conseguir aquello que desean de forma inmediata aun cuando perjudiquen para ello a los demás y si realizan algún favor a alguien de su entorno ya sean familiares o compañeros, lo harán a cambio de un beneficio a su favor. También diremos que estas dos características son de fácil detección porque no solo se desarrollará en casa, sino también frente a cualquier ámbito como el escolar o laboral. 


\subsection{Recapitulación}

Los factores desencadenantes y potenciadores que dan paso al ejercicio de conductas violentas a nivel general por parte de adolescentes y los factores sociales e individuales a nivel concreto, quedarían resumidos en la siguiente figura:

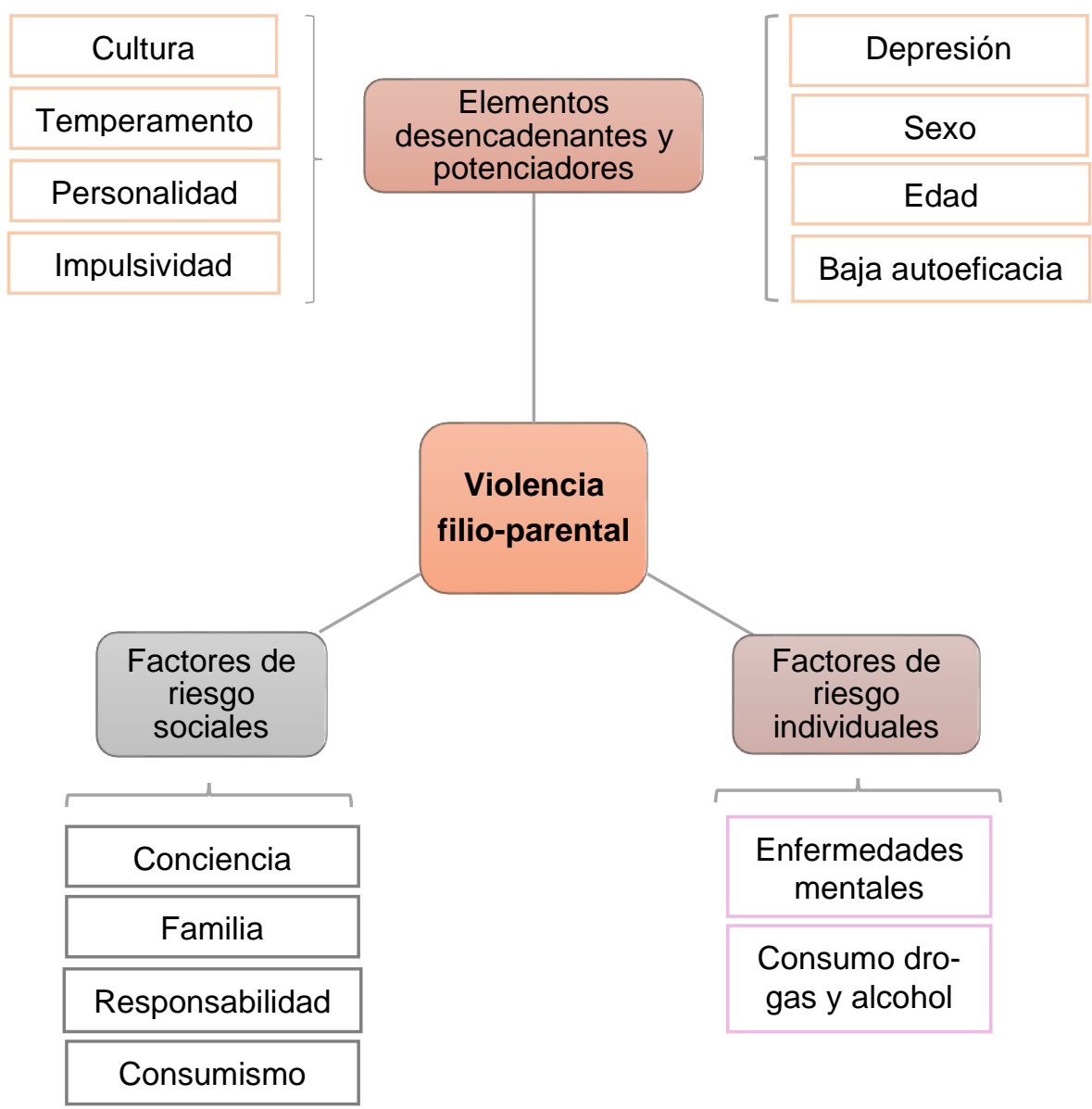

Figura 1. Factores influyentes en el joven agresor

A continuación, expondremos una serie de motivos del porqué los hijos pueden llevar a cabo conductas vejatorias hacia sus padres sin ningún tipo de remordimiento.

\section{Mecanismos inhibidores}

Una vez comentados a nivel general los elementos potenciadores y desencadenantes que pueden dar lugar a la conducta violenta y a nivel concreto, los factores sociales e individuales que influyen en el joven agresor, vamos a hablar de los motivos por los que estos no sienten ningún remordimiento a la hora de atacar a sus padres. Haremos referencia a los términos apego y empatía y a cómo la falta de estos según Sanmartín (2004, 
pp. 258-259) actuarán de mecanismos inhibidores de los sentimientos de culpa o arrepentimiento.

\subsection{La falta de apego y empatía}

El apego en las personas se va forjando a lo largo de la vida. La conducta del niño recién nacido se regirá por una serie de componentes genéticos para poder sobrevivir. Hablamos de simples gesticulaciones como llorar, una mirada o una sonrisa, estímulos que nos provocan terceras personas cuando somos bebés. Sin llegar a cumplir el año de edad, los niños reconocen la voz y el olor de los padres. Sonríen y balbucean ante cualquier estímulo que reciben de ellos. Se empieza a formar el apego humano puesto que, al dejar a los bebés en una habitación sin tener contacto humano, se enfadan o lloran.

En el siguiente periodo, el vínculo afectivo que se va forjando con los padres llega al punto de generar ansiedad a los niños a la hora de separarse de estos e irse con otra persona como puede ser otro familiar. Cuando los bebés dejan de serlo y empiezan a ser niños de 2 o 3 años, aparecen las primeras palabras y la percepción del entorno cuando no está su madre. La ansiedad es menor que en el periodo anterior puesto que el niño empieza a entender que su madre volverá junto a él.

La realización de estas fases con total plenitud da lugar a un vínculo afectivo sólido entre padres e hijos, donde el niño sentirá la seguridad de que sus padres responderán en el momento que los necesite.

Entonces, ¿a qué da lugar la falta de apego? Cuando el vínculo de afectividad que debería haberse forjado en los primeros años de vida no se lleva a cabo, el niño desarrollará una serie de miedos e inseguridades, lo que le llevara a actuar de forma rebelde y a no mostrar ningún tipo de emoción ante cualquier estímulo. Estos sujetos crecerán con carencia emocional y a lo largo de la vida pueden forjar una personalidad insegura y débil la cual podrán cambiar o no en la edad adulta dependiendo de si consiguen enfocar su vida de otra forma.

Una vez explicado el apego y las consecuencias de su ausencia, lo relacionaremos con las conductas que adoptarán estos niños frente a sus padres o terceros. Al no haberse sentido protegidos, cuidados, queridos, etc., serán personas frías, introvertidas y desconfiadas. Con el paso del tiempo, cuando alcancen la adolescencia, tomarán represalias contra sus padres debido a que esa frialdad recibida desde pequeños les habrá causado dificultades a la hora de relacionarse con la sociedad, culpando así a sus progenitores y adoptando conductas violentas sin ningún tipo de remordimiento. 
En cuanto a la empatía como segundo mecanismo inhibidor, es la capacidad que tenemos las personas para ponernos en el lugar de otros. El tener empatía con las otras personas hace que nazca la necesidad de querer ayudar a quien lo necesite. Existe un estrecho vínculo entre el haber forjado desde el nacimiento unos lazos afectivos (apego) y la empatía.

El adoptar una conducta empática nos lleva a adoptar una conducta prosocial, es decir, lo contrario a una conducta hostil, puesto que la empatía ayuda a controlar la agresividad y hace establecer lazos con otras personas que llegarán a ser amigos, parejas etc. Facilitando entonces el respeto a las personas, a las normas de convivencia, a las leyes, a la propiedad y también, facilitando la mediación frente a posibles situaciones violentas o de agresión.

Por lo tanto, la empatía y el apego van ligados. Si no se establece un apego sólido desde el nacimiento, la empatía puede darse por perdida y encontraremos un perfil en el que se habrá desarrollado un temperamento complicado, de alta impulsividad, poco autocontrol, pocas o nulas relaciones sociales y conductas agresivas. Estas características por supuesto van ligadas a los factores de riesgo sociales e individuales comentados anteriormente, dando respuesta al porqué los hijos llegan a agredir a sus padres.

\section{El síndrome del emperador}

Cuando atribuimos a un joven el llamado síndrome del emperador, es porque ha llevado al límite la violencia contra sus padres. Hablamos entonces de aquellos individuos que se han visto envueltos de todo lo comentado anteriormente, es decir, de los elementos desencadenantes y potenciadores, de los factores sociales e individuales y del desarrollo de algún tipo de trastorno o de rasgos psicopáticos.

Hablamos de adolescentes que pueden llegar a asesinar y cometer actos vejatorios hacia sus progenitores sin ningún tipo de remordimiento, el síndrome del emperador se caracteriza por una ausencia completa de conciencia y una serie de comportamientos orientados a atentar contra sus progenitores de forma abusiva y reiterada.

El nombre de dicho síndrome hace referencia a los emperadores de Roma como explica Garrido Genovés (2019, p. 74). Estos antiguamente creyéndose dioses en la tierra, podían decidir sobre la vida y la muerte de una persona con tan solo mover su 
dedo pulgar. Si la voluntad de estos sobre el sufrimiento de otras personas se cuestionaba o se discutía, era bien sabido que entrarían en cólera, siendo entonces los jóvenes que padecen este síndrome los nuevos emperadores.

Tal y como afirma Garrido Genovés (2009, pp. 66-72), existen tres claves imprescindibles a la hora de darse cuenta de si el hijo presenta características del síndrome del emperador. Estas claves se observan des los seis a los once años.

Primero hablamos de la incapacidad de desarrollar algún tipo de emoción como la compasión, la tristeza, la empatía, etc. La falta de estos sentimientos se puede observar en el momento en que el sujeto no se siente culpable tras haber cometido un comportamiento inadecuado que haya llevado a un castigo por parte de sus padres.

La segunda clave consiste en el sentimiento de no arrepentimiento sobre sus actos y el no entendimiento sobre el porqué de ese castigo ni del error que ha cometido, aun siendo explicado por sus padres una y otra vez. Además, el sujeto usará esta incomprensión a modo de victimismo para hacer sentir mal a sus padres y poder entonces aprovecharse de ello y obtener algún beneficio, es decir, manipulará la situación y jugará con los sentimientos de estos para que vean que la víctima es él.

La última clave consta de la observación de una serie de conductas habituales de desafío, crueldad y mentiras no solo hacia los padres, sino también hacia los otros miembros de la familia y amistades.

Estos comportamientos son fundamentales a la hora de detectar si el hijo padece este síndrome. Se tienen que dar de forma reiterada, no como hechos aislados que se puedan desatar en la adolescencia con normalidad, generalmente la mayor intensidad se dará en la preadolescencia siempre y cuando anteriormente se haya apreciado alguno de los síntomas comentados.

El sentimiento de culpa en los sujetos que padecen el síndrome del emperador juega un papel primordial, puesto que al no experimentar dicho sentimiento, no existe dolor ni remordimiento a la hora de dañar a los padres ni romper la armonía familiar, una problemática que cara al futuro del adolescente se extenderá a la sociedad.

Con el paso del tiempo, los jóvenes que presentan las características de dicho síndrome, con ayuda de los padres y en un ambiente donde la problemática se haya ido abordando desde su identificación, irán mermando el grueso de su mala conducta y podrán llegar a la edad adulta sin problemas de violencia. 
Sin embargo, existirá un menor número de jóvenes que tendrán dificultades a la hora de paliar su comportamiento, hablamos de niños que además de tener aparejados rasgos psicopáticos o trastornos mentales antisociales, también serán niños que no cuenten con unos padres entregados y capacitados para poner fin a la situación.

\section{Cambio de rumbo. El deber de las partes.}

Cuando nuestro hijo desde la infancia presenta una serie de conductas inapropiadas como puede ser la impulsividad o la ira cuando no consigue aquello que quiere, se tiene que cambiar el rumbo para evitar que estas conductas vayan a más y acaben convirtiéndose en futuros emperadores. Para conseguir cambiar esto es primordial que los padres y los hijos a su vez, asimilen y aprendan una serie de aspectos fundamentales.

\subsection{Los padres}

Una vez los padres detecten que su hijo de forma poco esporádica pero no continua adoptan comportamientos negativos, tienen que ver que este necesita aprender sobre autocontrol, para que con el paso del tiempo no se convierta en algo reiterado.

Este aprendizaje se logrará en el momento en que los padres le hagan ver al niño que el control lo tienen ellos sin ningún tipo de temor o debilidad ante el enfado del hijo cuando no consigue aquello que quiere, es decir, los padres tienen que dar una imagen fuerte y sólida puesto que uno de los primeros síntomas en aquellos niños que padecerán el síndrome del emperador es la manipulación. Si los padres adoptan esta posición de valentía, los niños no tendrán la misma autoconfianza para poder salirse con la suya y poder manipularles mediante el sentimiento de culpa. A esto se le tiene que añadir que los padres tienen que verse capaces y seguros, confiando plenamente en que el cambio hacia un mejor comportamiento se va a conseguir, es decir, tienen que ser optimistas.

Junto a esta actitud añadiremos la objetividad. Los padres tienen que ser objetivos y aceptar que ciertos comportamientos que ven en el niño no son apropiados. A la hora de hablar del tema con amigos, profesores u otros familiares, tienen que reconocer que han de prevenir el empeoramiento de dicho comportamiento. Esta labor no es sencilla, puesto que, como hemos comentado anteriormente, los niños harán uso de la manipulación emocional con los padres para hacerlos sentir mal. Es cuando los niños culpan a sus padres diciendo por ejemplo que no les quieren cuando ellos tienen que ceñirse a 
lo que ven y viven en casa dejando apartada dicha emoción. Tal y como afirma Garrido Genovés (2019, pp. 105-107), si los padres reaccionan o responden ante las emociones que presentan sus hijos en vez de a sus conductas, intentarán no ser muy estrictos por el temor a que estos se intenten fugar de casa, del colegio, etc. Es por este motivo por lo que los padres tienen que tomar decisiones contundentes frente a los hijos y explicarle el motivo que los ha llevado a tomar esas decisiones. Decir las cosas sin humillar y sin necesidad de amenazar ni atentar contra las emociones del hijo. Un ejemplo sería "Ni tu madre, ni tu padre, ni tu hermana vamos a tolerar un comportamiento como el tuyo en esta casa" y a continuación, exponerle de qué comportamientos se habla.

Una vez los padres hayan conseguido establecer en su modo de educar la valentía y la objetividad de las que hemos hablado, conseguirán salir del agujero en el que se encontraban cada vez que su hijo adoptaba conductas inapropiadas. Al final, lo que se pretende con esto no es hacer de nuestro hijo una persona perfecta, sino alguien que sepa diferenciar lo que está bien de lo que está mal y que de cara al futuro sea una persona con amplios aspectos positivos.

Para poder frenar estos antecedentes y poder alcanzar el resultado, no solo basta con el trabajo que tienen que ejercer los padres como educadores, también los hijos tendrán que adoptar una serie de cambios que explicaremos a continuación.

\subsection{Los hijos}

Los niños que presentan síntomas del síndrome del emperador, con la ayuda de sus padres y si hiciese falta de profesionales, tendrían que aceptar que la violencia de la que hacen uso y la manipulación que ejercen en sus padres cuando quieren conseguir alguna meta no son eficaces. Una vez aceptado esto, se tendría que intentar que ellos mismos adoptasen, a la hora de comunicarse con los padres, el valor de negociar a cambio de un compromiso.

Otro aspecto que tendría que aprender el niño sería el autocontrol. La mayoría de las veces aquello que desean y se les niega es lo que hace que pierdan el control, no contemplan ninguna razón por lo que mantener el control ante la negativa. Si cuando se da una situación así, los padres toman medidas de autocontrol como por ejemplo contar hasta 10, mirar fijamente al hijo unos segundos y girarse abandonando la sala donde este se encuentre, el hijo percibirá que con su actitud no consigue nada. 
Por último, al hablar de niños que se acercan a la adolescencia, que es cuando el síndrome del emperador está en pleno apogeo, sabemos que su apariencia física cara a los demás es muy importante como hemos comentado anteriormente. La aprobación social y el reconocimiento juegan un papel primordial en la cabeza del adolescente, por ello los padres tienen que jugar un papel en el que hagan ver que su hijo es diferente a los demás niños y que su comportamiento negativo no solo influye en casa, sino también en el colegio, en la familia y en los amigos.

\subsection{Medidas de ayuda}

Lo comentado anteriormente sobre el comportamiento de los padres y los hijos enfocado a la mejora, será posible en aquellos jóvenes que cuenten con la ayuda de sus padres y con un entorno que influya de manera favorable a su cambio de comportamiento. Sin embargo, también existirán jóvenes que tendrán dificultades a la hora de paliar su comportamiento, hablamos de niños que además de tener aparejados rasgos psicopáticos o trastornos mentales antisociales, no cuenten con unos padres entregados y capacitados para poner fin a la situación.

Por lo que respecta a este tipo de jóvenes encontrarán más dificultades a la hora de modificar el comportamiento. A continuación, expondremos una serie de medidas para poder hacer frente a estas personas y en cierta forma "tenderles la mano".

La primera medida sería en referencia a la sociedad. No por ver que son personas solitarias y a las que los grupos rechazan, debemos hacer lo mismo. Tratar al individuo como lo tratan los demás lo único que hará será repercutir en este de forma negativa. Con cada desprecio se sentirá más diferente y esto no le ayudará a integrarse ni a confiar en sí mismo, debemos darle la oportunidad de pertenecer a un grupo sin ningún tipo de discriminación.

La segunda medida trata sobre los padres. Aquellos que no sean competentes y se vean incapaces de hacer frente al comportamiento de su hijo, son conscientes de que no lo hacen bien y ellos mismos se sienten mal. La mayoría de las veces no acuden a ayuda profesional ni toman medidas judiciales en contra de las agresiones de sus hijos, por lo que esta medida pretende que la sociedad no señale a ambos si interviene la autoridad en la familia, sino más bien, apoyar el paso que han dado sin hacerlos sentir avergonzados.

Otra medida sería la atención domiciliaria. Crear unidades de atención especializada formadas por grupos de psicólogos, criminólogos y educadores que tendrían que acudir 
al lugar de residencia del joven tirano para así elaborar un informe sobre el comportamiento que adopta el sujeto. Una vez analizado esto, ayudar a los padres o a las personas que convivan con él mediante una serie de pautas y un seguimiento personalizado.

Por último, la cuarta medida sería en relación a las escuelas. Dotar a estas de profesores y materiales para poder atender a los niños que tienen comportamientos negativos, así podremos intervenir en el comportamiento del sujeto para corregirlo y además evitar que se produzcan agresiones contra otros compañeros (bullying). De no ser así, los niños que tienen comportamientos desviados y agreden a otros niños, una de dos, o se ven reforzados como "lideres" del grupo por el temor que implantan o se verán aislados. Ambas situaciones repercutirían de forma negativa en el sujeto, puesto que las dos desembocarían en la continuidad de su conducta.

Podremos evitar que el problema aumente en el futuro llevando a cabo estas medidas con niños que no cuentan con la ayuda de sus padres, ya sea porque es una familia desestructurada o porque a los padres "se les queda grande" la situación. Trabajar con ellos, sobre todo en el colegio, donde se encuentran los segundos educadores es primordial, para que cuando llegue a una edad de madurez pueda entender todo lo que se ha ido trabajando con él. Ayudar a estos niños es labor de los padres, de la sociedad y del sistema educativo.

\section{Esperanza en el cambio y resiliencia}

Cuando se plantea el propósito de cambiar a un joven tirano, se tiene que tener en cuenta que no se volverá un chico encantador y adorable como otro que prácticamente desde el nacimiento lo haya sido. Lo que debemos entender es que, con la ayuda, lo que se conseguirá es que el sujeto pueda establecer una conducta apropiada en cualquier terreno de la vida, ya sea en el ámbito familiar, laboral o social.

Esto no siempre es tan bonito, puesto que el adolescente que presente rasgos psicopáticos debido a su personalidad puede llegar a manifestarlos cuando se enfade. Ante esta situación lo más importante es no desanimarse y seguir luchando contra estos comportamientos, ya que en la adolescencia la personalidad se ve incrementada en comparación a la edad adulta debido a la cantidad de cambios que padece el cuerpo, por lo que entenderemos, que mientras el cambio lo llevemos a cabo durante la adolescencia, existe un margen de mejora y avance hasta la edad adulta. 
La meta más importante de los padres será que sus hijos puedan tratar a los demás con un respeto mínimo, actuando ante las posibles conductas negativas que estos lleven a cabo.

La resiliencia es un concepto que define muy bien el enfoque de esta nueva meta. Este concepto se puede aplicar tanto a los jóvenes tiranos como a los padres que sufren las agresiones y luchan por paliarlo. Hablamos de un término que se refiere a las personas que tienen la capacidad para superar una serie de circunstancias y vivencias que les han causado malestar y lo asocian con una serie de experiencias traumáticas. Este fenómeno puede desarrollarse en mayor o menor grado de plenitud, existen personas que son más resilientes que otras, algo que va acorde a la personalidad de cada uno.

Para poder desarrollar esta capacidad, lo más importante es el modo en el que pensamos, se tiene que hacer de forma en el que siendo conscientes de que existe un problema, no es algo horrible que no se pueda afrontar, todo lo contrario, tomarlo como un reto que afrontar.

Otro aspecto que influirá en la resiliencia será el círculo de iguales del que formamos parte. Si nos juntamos con personas que nos ayudan a afrontar los problemas y nos aconsejan sobre cómo actuar ante ciertas situaciones que nos vienen grandes, nos será más fácil ser resilientes porque a pesar de las adversidades, nos veremos respaldados por estos. Sin embargo, si en el grupo del que formas parte los problemas y malas conductas que se dan son aquellas que tú quieres cambiar, no encontrarás apoyo, puesto que entre ellos estas conductas se verán reforzadas y te tratarán como distinto, haciéndote sentir peor.

Otra pauta para poder ser una persona resiliente es la de confiar en uno mismo y ser optimista. Tienes que apostar y confiar en ti dando pasos firmes y seguros en cada decisión que tomes, para demostrarte así que eres capaz de controlar tu vida y que cuando venga alguna adversidad sabrás gestionarlo.

Muchas veces nos abordan situaciones problemáticas y pensamos que es imposible resolverlas, esto lo único que hace es que nos frustremos más y nos invada un sentimiento de impotencia que nos acabará bloqueando ante la búsqueda de posibles soluciones. Pero la realidad de esto es que no somos conscientes de lo que podemos llegar a hacer hasta que no lo intentamos y al final, con tiempo y dedicación conseguiremos más que sin haber intentado nada. Adaptarnos a esta serie de habilidades para convertirnos en personas resilientes, nos permitirá tener esperanza en el futuro y superar situaciones donde mucha otra gente no ve salida. 


\section{Conclusiones y recomendaciones}

Como hemos comentado a lo largo del trabajo, son varios los factores que influyen de manera negativa en el individuo que comete actos violentos contra sus padres. Hemos hecho referencia a diferentes tipos de violencia, siendo estas la física, psicológica y económica, y, tras ello, hemos desarrollado una serie de elementos potenciadores que, unidos a los factores sociales e individuales, hace estallar dicha conducta.

Hablamos entonces del tipo de cultura en la que estamos inmersos, de la personalidad con la que nace el individuo que caracterizará su temperamento e impulsividad, la edad, el sexo y la baja autoeficacia unidos a factores sociales e individuales, como el padecer un trastorno mental y el abuso de sustancias tóxicas, la necesidad de satisfacer los deseos materiales de forma inmediata, las rupturas familiares, el estrés y la falta de conciencia.

La suma de estos elementos potenciadores y de los factores de riesgo sociales e individuales, son los que darán lugar a la conducta que adopte el individuo, pero esto no es todo, ya que como hemos explicado en puntos anteriores, también influirá la falta de apego y empatía, ya que no existirá ningún mecanismo natural que haga frenar estos actos violentos haciendo sentir arrepentimiento en el sujeto.

Como hemos podido observar, todo lo que forma al adolescente violento es el cúmulo de una serie de elementos negativos que se manifestarán, además, de un modo narcisista y egocéntrico, dando lugar incluso a personas con rasgos psicopáticos.

A modo de conclusión y en relación a todos estos factores, podemos afirmar la existencia de una razón clara de porqué lleva al fracaso las personas que adoptan estas conductas violentas. Hablamos del fracaso de no poder disfrutar de una vida plena con todo lo que esto conlleva, es decir, vivir con sentido, el enfocar la vida hacia un proyecto en el que día a día se va construyendo y que al final, puedas dejar el mundo con la sensación de haber aportado un granito de arena en la época en la que viviste.

Cuando hablamos de personas jóvenes que únicamente se obsesionan por su imagen y por aquello que quieren obtener, cuando lo único que les hace sentir emociones es el mal que ocasionen a terceros y cuando lleven la irresponsabilidad por bandera, es cuando tendremos certeza de que con el paso del tiempo se convertirá en la viva imagen del fracaso. 
Para evitar que estos adolescentes lleguen a este punto, se deberían de tomar una serie de recomendaciones que involucrasen a todas aquellas personas que puedan tener el más mínimo contacto con el agresor. Hablamos del conjunto familiar, de los compañeros de clase, de los profesores, de la sociedad, etc.

Sería recomendable no dar un caso de violencia filio-parental por perdido sin antes no haber intervenido para ayudar a reconducir las vidas de estos adolescentes. Los padres, siendo el pilar fundamental, son los primeros que deberían de tomar medidas al respecto y si la situación ha sobrepasado sus límites, solicitar la ayuda de profesionales dejando de lado el sentimiento de culpa y llenándose de valentía para reconocer que necesitan la intervención de terceros.

Además, también sería aconsejable que aparte de la intervención de los padres o profesionales, las personas cercanas a ellos tratasen el tema con naturalidad, para así verse los padres respaldados y apoyados psicológica y moralmente por estos. En cuanto a los compañeros o amigos que rodeasen al joven, deberían de hacerle entender que no adopta una conducta apropiada, sin tener que marginarlo o dejarlo en evidencia delante de los demás.

Resulta una tarea difícil para los padres cambiar el curso de la vida de un hijo violento, pero si en este cambio intervenimos todos los comentados anteriormente, lo difícil se convertiría en algo más sencillo.

\section{Bibliografía}

- Abadía Selma, A. (2015) La violencia filio-parental y la reinserción del menor infractor. Consideraciones penales y criminológicas. Tesis doctoral. Uned. Disponible en: http://espacio.uned.es/fez/eserv/tesisuned:Derecho-Aabadias/ABADIAS SELMA Alfredo Tesis.pdf [Descargado 12-01-2020]

- Agnew, R. (1992) "Foundations for a general strain theory of crime and delinquency", Criminology, 30, pp. 47-87.

- Aguilar Cárceles, M. M. (2017) "La inadecuada identificación de la psicopatía con el trastorno antisocial de la personalidad", Revista Electrónica de Ciencia Penal y Criminología, (14-13), pp. 5-10. Disponible en: http://criminet.ugr.es/recpc/19/recpc19-13.pdf [Descargado 12-01-2020] 
- Benedicto Duque, C. (2015) "Salud mental y violencia filio-parental", en Actas del ler. Congreso Nacional de VFP, Madrid, pp. 483-488.

- Berkowitz, L. (1990) "On the formation and regulation of anger and aggression: A cognitive-neoassocionistic analisis", American Psychologist, 45, pp. 494-503.

- Blau, P.M., \& Blau, J.R. (1982) "The cost of inequality: metropolitan structure and violent crime", American Sociological Review, 47, pp. 114-129.

- Chichilla, M. J., Gascó, E., Gracia, J. y Otero, M. (2005) "El maltrato a la infancia. Informe especial sobre los malos tratos en el seno familiar y la violencia de hijos a padres.", Boletín Oficial de las Cortes de Aragón, 153, pp. 6838-6864. Disponible en: http://bases.cortesaragon.es/bases/original.nsf/(BOCA1)/51BF281858709A99C125706F002E4518/\$File/BocaVI 153.pdf?OpenElement [Consultado 12-01/2020]

- Cuervo, A. y Rechea, C. (2009) "Menores agresores en el ámbito familiar", Centro de Investigación en Criminología Universidad Castilla-La Mancha, Informe nº. 17. Disponible en: $\underline{\text { http://www.uclm.es }}$

- Defensor del Menor de Andalucía (2014) La atención a menores infractores en centros de internamiento de Andalucía, p. 214. Andalucía: defensor del menor de Andalucía. Disponible en: http://www.defensordelmenordeandalucia.es/sites/default/files/informe atencion a menores infractores xs 0. pdf

- Fundación Amigó (2018) Violencia filio-parental en España. Disponible en: https://www.fundacionamigo.org/wp-content/uploads/2018/02/vfp2018.pdf

- Garrido Genovés, V. (2009) "Hijos maltratadores. ¿Qué es el Síndrome del emperador?", Crítica 59 (964), pp. 66-72. Disponible en: http://www.revista-critica.com/administrator/components/com avzrevistas/pdfs/38a777040ca01ecc623923098db31516-964Educar-las-emociones-nov-dic-2009.pdf

- Garrido Genovés, V. (2019) “Los hijos tiranos. El síndrome del emperador”, Barcelona: Ariel.

- Hare, R.D. (2003) Sin Conciencia: El Inquietante Mundo de los Psicópatas que nos Rodean. Barcelona: Ediciones Paidos.

- Ibabe, I., Jaureguizar, J. y Díaz, O. (2007) Violencia filio-parental: conductas violentas de jóvenes hacia sus padres, pp. 26-27. Vitoria-Gasteiz: Servicio Central de Publicaciones del Gobierno Vasco. 
- Larraín, M, E. Y Monserrat Arrieta C. (2010) “Adolescencia: Identidad, Moda y Narcisismo", Revista de comunicación, 9, pp. 174-189 [Descargado 12-01-2020]

- Lázaro J.M., (2005) “Subida "desmesurada" del maltrato a padres”, El País, 14 de septiembre de 2005, disponible en: http://elpais.com/diario/2005/

- Luengo, M.A. y Carrillo, M.T. (1995) “La psicopatía”, En: Belloch Fuster, A., Sandín Ferrero, B. y Ramos Campos, F. Eds. Manual de Psicopatología 2, pp. 615- 650. Madrid: McGraw-Hill.

- Sanmartín, J. (2004) “El laberinto de la violencia”, Barcelona: Ariel.

- Torres Ayala, R., (2018) La violencia filio-parental: causas, fases y cómo poner remedio a las actitudes de tu hijo. Disponible en: https://www.unir.net/derecho/revista/noticias/laviolencia-filio-parental-causas-fases-y-como-poner-remedio-a-las-actitudes-de-tuhijo/549203636356/ [Consultado 09-01-2020] 